\title{
Effect of electron irradiation on the transformation characteristics of narrow hysteresis TiNiCu shape memory alloys
}

\author{
X. T. $\mathrm{Zu}^{\mathrm{a})}$ and L. M. Wang \\ Department of Nuclear Engineering and Radiological Sciences, University of Michigan, \\ Ann Arbor, Michigan 48109 \\ Y. Huo \\ Shanghai Institute of Ceramics, Chinese Academy of Sciences, \\ Shanghai 200050, People's Republic of China \\ L. B. Lin, Z. G. Wang, T. C. Lu, L. J. Liu, and X. D. Feng \\ Department of Physics/Key Laboratory for Radiation Physics and Technology of Education Ministry of \\ China, Sichuan University, Chengdu 610064, People's Republic of China
}

(Received 16 July 2001; accepted for publication 24 October 2001)

TiNiCu shape memory alloy samples were irradiated by $1.7 \mathrm{MeV}$ electrons below the martensite finish temperature $M_{f}$. The transformation temperatures and the latent heat of phase transformation were measured by differential scanning calorimeter. The damage accumulation was determined by positron annihilation technology. The results indicated that the austenite transformation temperatures were raised, and the hysteresis was increased by the irradiation. The electron irradiation had a slight effect on $M_{f}$, and no detectable effect on the martensitic transformation start temperature $M_{s}$. The second lifetime of positrons were increased by the electron irradiation indicating the increase in the size and amount of vacancy clusters, which contributed to the observed change of the transformation characteristics. (C) 2002 American Institute of Physics.

[DOI: $10.1063 / 1.1427747$ ]

Coupling devices and actuators using shape memory alloys (SMAs) are attracting interest for applications in the fields of nuclear engineering and space technology. ${ }^{1-3}$ For this purpose, it is necessary to know the effect of irradiation on the shape memory behavior of the alloys. There have been several studies on the change of shape memory characteristics of TiNi and CuZnAl SMAs after neutron, proton and electron irradiation. ${ }^{2-10}$ The results indicated that the irradiation can have a very strong influence on the transformation temperatures and the mechanical behavior of SMAs.

Comparing with TiNi and Cu-base SMAs, the ternary TiNiCu shape memory alloy has a much smaller hysteresis in transformation temperatures and pseudoelasticity and a much lower flow stress for martensitic reorientation. It is also much less sensitive to aging effects. ${ }^{3}$ Therefore, TiNiCu is a better candidate for many applications such as electrical connectors, sensors and actuators. Unlike the near equal atomic TiNi alloys, the martensitic transformation in this $\mathrm{TiNiCu}$ alloy is from $\mathrm{B} 2$ to $\mathrm{B} 19$, without $\mathrm{Ti}_{3} \mathrm{Ni}_{4}$ precipitation and $R$-phase transformation. ${ }^{3,4}$ Thus, its irradiation effect might be different from that in TiNi. However, as far as the authors' knowledge is concerned, the irradiation effect of $\mathrm{TiNiCu}$ SMA has not been reported. In this work, the irradiation effect on the transformation temperatures, the latent heat of phase transformation and the defect production of $\mathrm{TiNiCu}$ SMA have been studied by means of $1.7 \mathrm{MeV}$ electron electrostatic accelerator, differential scanning calorimeter (DSC) and positron annihilation technology (PAT).

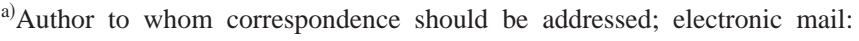
xiaotaozu@yahoo.com; permanent address: Department of Physics, Sichuan University, Chengdu, 610064, People's Republic of China.
Ti-43 at. \% Ni-7 at. \% Cu SMA samples with a thickness of $0.30 \mathrm{~mm}$, provided by the Northwest Institute of Non-Ferrous Metal of China, were annealed at $773 \mathrm{~K}$ for 30 min in an evacuated silica tube and then cooled in the air. As shown in Table I, after the heat treatment, the samples were then irradiated in air to the electron dose $(E=1.7 \mathrm{MeV})$ of $5.5,11.1$, and $17.4\left(\times 10^{20} \mathrm{~m}^{-2}\right)$ at the dose rate of 4.4 $\times 10^{16} \mathrm{~m}^{-2} \mathrm{~s}^{-1}$ in the Electron Electrostatic Accelerator of the Key Laboratory for Radiation Physics and Technology of Education Ministry of China located in Chengdu. The temperature of the samples during the irradiation was controlled by circulating water and was maintained at about $298 \mathrm{~K}$ monitored by a thermocouple, well below the martensitic transformation finish temperature $M_{f}$ (shown in Table II). Thus, the samples have been kept in the martensitic phase during the electron irradiation.

The irradiated samples were placed at room temperature for about 20 days then, the transformation temperatures were measured by DSC between 200 and $400 \mathrm{~K}$ at a rate of 10 $\mathrm{K} \min ^{-1}$.

On a conventional fast-fast coincidence setup (ORTEC) with NEIII scintillators and a time resolution of $235 \mathrm{ps}$, the positron annihilation lifetime was measured at room tem-

TABLE I. Experimental conditions of the electron irradiation.

\begin{tabular}{lc}
\hline \hline Samples & $\begin{array}{c}\text { Conditions of the electron irradiation with an energy } \\
\text { of } 1.7 \mathrm{MeV} \text { and a dose rate of } 4.4 \times 10^{16} \mathrm{~m}^{-2} \mathrm{~s}^{-1}\end{array}$ \\
\hline 1 & $\begin{array}{c}\text { Unirradiated } \\
2\end{array}$ \\
3 & $\begin{array}{l}\text { Irradiated for } 3.5 \mathrm{~h} \text { to a dose of } 5.5 \times 10^{20} \mathrm{~m}^{-2} \\
\text { Irradiated for } 7 \mathrm{~h} \text { to a dose of } 11.1 \times 10^{20} \mathrm{~m}^{-2}\end{array}$ \\
\hline
\end{tabular}


TABLE II. Transition temperatures of the martensitic transformations of TiNiCu SMA samples, before and after electron irradiation, measured by DSC.

\begin{tabular}{lccccc}
\hline \hline Samples & $\begin{array}{c}\text { Dose } \\
\left(10^{20} \mathrm{~m}^{-2}\right)\end{array}$ & $\begin{array}{c}A_{s} \\
(\mathrm{~K})\end{array}$ & $\begin{array}{l}A_{f} \\
(\mathrm{~K})\end{array}$ & $\begin{array}{l}M_{s} \\
(\mathrm{~K})\end{array}$ & $\begin{array}{l}M_{f} \\
(\mathrm{~K})\end{array}$ \\
\hline 1 & 0 & 322 & 336 & 318 & 305 \\
2 & 5.5 & 325 & 339 & 318 & 304 \\
3 & 11.1 & 334 & 346 & 320 & 311 \\
4 & 17.4 & 335 & 346 & 319 & 309 \\
\hline \hline
\end{tabular}

perature with the source ${ }^{22} \mathrm{Na}$ sandwiched between two electropolished, identical samples. The computer program, Positronfit, was used for the lifetime spectrum fitting with a total count over $10^{6}$.

The DSC curves of the electron irradiated and the unirradiated samples are shown in Fig. 1. The transformation temperatures are listed in Table II $\left(M_{s}, M_{f}\right.$ and $A_{s}, A_{f}$ is the martensitic transformation start, finish temperature and austenite transformation start, finish temperature, respectively). The positron annihilation second lifetime of the samples is shown in Fig. 2.

It is obvious from Fig. 1 and Table II that the transformation temperatures $A_{s}, A_{f}$, and $M_{f}$ of TiNiCu SMA were increased by the electron irradiation but the irradiation up to the dose of $17.4 \times 10^{20} \mathrm{~m}^{-2}$ had no detectable effect on $M_{s}$ so the martensitic phase was stabilized ${ }^{11-13}$ by the irradiation in the sense that the reverse transformation temperatures were higher than before. This is different from the results of neutron irradiated TiNi SMA, for which a strong decrease of the transition temperatures was observed. ${ }^{6}$

Figure 2 shows clearly that the defect lifetime $\tau_{2}$ increased with the irradiation dose. This implies that the size and the amount of the vacancy clusters in the samples had been increased by the irradiation. ${ }^{14}$ Moreover, the unirradiated sample had a $\tau_{2}$ of about 300 ps, so the vacancies in the

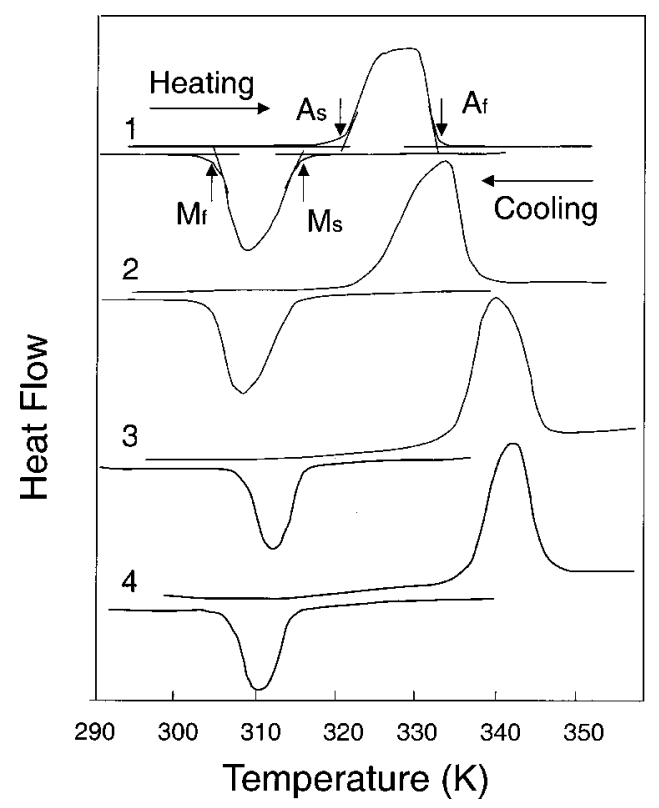

FIG. 1. DSC results of TiNiCu specimen showing that the martensitic transformation was shifted to higher temperatures after electron irradiation: (1) unirradiated, (2), (3), (4) are from samples irradiated to 5.5, 11.1, 17.4 $\times 10^{20} \mathrm{~m}^{-2}$, respectively. The characteristic temperatures $\left(M_{s}, M_{f}, A_{s}, A_{f}\right)$ of the transformation are listed in Table I.

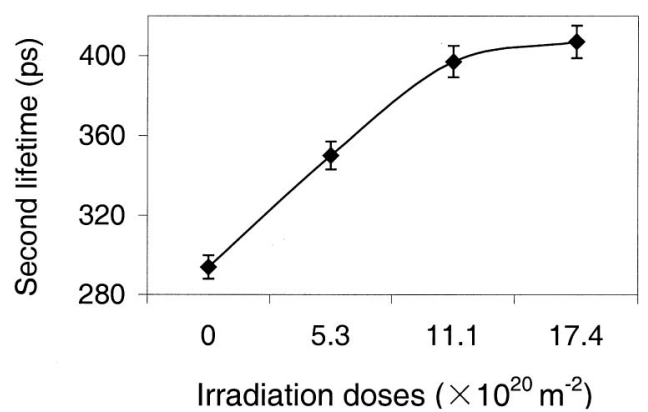

FIG. 2. Increase of the positron annihilation second lifetime (ps) of $\mathrm{TiNiCu}$ SMA samples with the electron irradiation doses.

sample are so-called divacancy or vacancy clusters. ${ }^{15}$ This might be mainly due the internal twin or slip structures of its orthorhombic B19 martensite and the twin boundaries between martensitic variants. Since the range of the $1.7 \mathrm{MeV}$ electron beam $(\sim 1 \mathrm{~mm})^{16}$ is much larger than the thickness of the samples $(\sim 0.3 \mathrm{~mm})$, the electrons had penetrated through the whole sample and had produced evenly distributed Frenkel point defects (interstitials and vacancies). Some point defects may migrate to the exiting microstructure defects (twin boundaries and dislocations) modifying the local atomic configuration, and some may accumulate to form defect clusters.

Since the amount of the changes in the transformation temperatures $M_{s, f}$ and $A_{s, f}$ are not all the same, the electron irradiation had affected the transformation hysteresis defined by $A_{s}-M_{s}$ or $A_{f}-M_{s}$ and the stored elastic energy related to $M_{s}-M_{f}$ or $A_{f}-A_{s}$. The equilibrium temperature $T_{0}$ between the martensitic and the parent phase is the temperature at which the Gibbs free energies (the chemical term) of the two phases are equal, ${ }^{3,17}$ which is approximately equal to $1 / 2\left(M_{s}+A_{f}\right) .^{17,18}$ The hysteresis in the transformation can be represented by the overheating $A_{f}-T_{0}=1 / 2\left(A_{f}-M_{s}\right)$ which is related to the driving force for the nucleation of the parent phase. $^{18}$

Table III lists the values of $T_{0}, A_{f}-T_{0}, M_{s}-M_{f}$, and $A_{s}-M_{s}$ of the samples calculated from Table II, it is clear that the thermodynamic equilibrium temperature $T_{0}$ of the martensitic and the parent phase was raised by the electron irradiation. Thus, the martensite was stabilized by the electron irradiation $^{12,19}$ and the Gibbs free energy of the martensite was lowered with respect to the parent phase, which led to a higher equilibrium temperature $T_{0}$. This might be due to the irradiation induced disordering of the crystallographic structure.

Table III shows that the hysteresis of the martensitic phase transformation $A_{f}-T_{0}$ and $A_{s}-M_{s}$ had been increased significantly by the electron irradiation. At the same time

TABLE III. Irradiation effects on $T_{0}, A_{f}-T_{0}, A_{s}-M_{s}$, and $M_{s}-M_{f}$ of TiNiCu SMA samples calculated from Table II.

\begin{tabular}{lccccc}
\hline \hline Samples & $\begin{array}{c}\text { Dose } \\
\left(10^{20} \mathrm{~m}^{-2}\right)\end{array}$ & $T_{0}(\mathrm{~K})$ & $\begin{array}{c}A_{f}-T_{0} \\
(\mathrm{~K})\end{array}$ & $\begin{array}{c}A_{s}-M_{s} \\
(\mathrm{~K})\end{array}$ & $\begin{array}{c}M_{s}-M_{f} \\
(\mathrm{~K})\end{array}$ \\
\hline 1 & 0 & 327 & 9 & 3 & 14 \\
2 & 5.5 & 328 & 11 & 7 & 14 \\
3 & 11.1 & 333 & 13 & 13 & 9 \\
4 & 17.4 & 333 & 13 & 16 & 10 \\
\hline \hline
\end{tabular}


$M_{s}-M_{f}$ had decreased slightly after $7 \mathrm{~h}$ electron irradiation for dose values of 11.1 and $17.40\left(\times 10^{20} \mathrm{~m}^{-2}\right)$. As indicated by the positron annihilation measurement of Fig. 2, the irradiation raised the size and amount of vacancy clusters to resist the phase transformation. This would result in a higher driving force needed for the austenite nucleation, thus a larger overheating $A_{f}-T_{0}$. On the other hand, since the irradiation was performed in the martensitic phase of the sample, some of the point defects produced by the electron irradiation would migrate to the exiting twin boundaries of martensite leading to a relaxation of the stored elastic energy and a slight decrease of $M_{s}-M_{f}{ }^{7}$

The electron irradiation increased the austenite transformation temperatures and hysteresis of TiNiCu SMAs, and had a slight effect on $M_{f}$ and no effect on $M_{s}$. Thus, the martensite was stabilized by the irradiation. The overheating needed for the austenite nucleation was raised by about $50 \%$ and the difference between $M_{s}$ and $M_{f}$ decreased by $30 \%$ after the irradiation by electrons to a dose of 11.1 $\times 10^{20} \mathrm{~m}^{-2}$.

The results of positron annihilation spectroscopy had shown that the second lifetime of positrons was increased by the electron irradiation so, the size and amount of vacancy clusters was raised and this contributed to the observed change of the transformation characteristics of the electron irradiated TiNiCu SMAs.

This study was supported by the China National Natural Science Foundation for Outstanding Overseas Young Scien- tist, the Visiting Scholar Foundation of Key Laboratory for Radiation Physics and Technology of Education Ministry of China, the Excellent Faculty Funding and the Ph.D. Funding Support Program of Education Ministry of China.

${ }^{1}$ M. Nishikawa, T. Narikawa, M. Iwamoto, and K. Watanabe, Fusion Technol. 9, 101 (1986).

${ }^{2}$ T. Hoshiya, M. Ohmi, Y. Matsui, and F. Nishikawa, J. Nucl. Mater. 258263, 2036 (1998).

${ }^{3}$ Shape Memory Materials, edited by K. Otsuka and C. M. Wayman (Cambridge University Press, London, 1998), p. 49.

${ }^{4}$ Z. G. Wei, R. Sandstrom, and S. Miyazaki, J. Mater. Sci. 33, 3743 (1998).

${ }^{5}$ J. Cheng and A. J. Ardell, Nucl. Instrum. Methods Phys. Res. B 44, 336 (1990).

${ }^{6}$ T. Hoshiya, S. Den, H. Ito, S. Takamura, and Y. Ichihashi, J. Jpn. Inst. Met. 55, 1054 (1991).

${ }^{7}$ E. Goo and A. Murthy, Scr. Metall. Mater. 29, 553 (1993).

${ }^{8}$ A. Barbu, A. Dunlop, A. H. Duparc, G. Jaskierowicz, and N. Lorenzelli, Nucl. Instrum. Methods Phys. Res. B 145, 354 (1998).

${ }^{9}$ Y. Matsukawa and S. Ohnuki, J. Nucl. Mater. 239, 261 (1996).

${ }^{10}$ Z. H. Dughaish, Mater. Lett. 32, 29 (1997).

${ }^{11}$ C. Segui, Scr. Metall. Mater. 32, 565 (1995).

${ }^{12}$ J. Van Humbeeck, J. Janssen, Mwambangoie, and L. Delaey, Scr. Metall. 18, 893 (1984).

${ }^{13}$ K. Shimizu, Y. Nakata, and O. Yamamoto, Mater. Res. Soc. Symp. Proc. 246, 43 (1992).

${ }^{14}$ R. W. Siegel, Positron Annihilation, edited by P. G. Coleman, S. C. Sharma, and L. M. Diana (North-Holland, Amsterdam, 1982), p. 351.

${ }^{15}$ J. Hurtado, D. Segers, J. Van Humbeek, L. Dorikens-Vanpraet, and C. Dauwe, Scr. Metall. Mater. 33, 741 (1995).

${ }^{16}$ L. E. Glendennin, J. Nucleonics 12, 2 (1948).

${ }^{17}$ C. M. Dunne and C. M. Wayman, Metall. Trans. 4, 137 (1973).

${ }^{18}$ Y. Huo and X. Zu, Continuum Mech. Thermodyn. 10, 179 (1998).

${ }^{19}$ Y. J. Kong, B. Jiang, T. Y. Hsu, B. Y. Wang, and T. M. Wang, Phys. Status Solidi A 133, 269 (1992). 